\title{
Experimental Study on Deformation and Strength Characteristics of Sandstone with Different Water Contents
}

\author{
S. R. Wang ${ }^{1,2^{*}}$, P. Hagan ${ }^{1,2}$, Y. C. Li ${ }^{2}$, C. G. Zhang ${ }^{2}$ and X. L. Liu ${ }^{2}$ \\ ${ }^{1}$ International Joint Research Laboratory of Henan Province for Underground Space Development and Disaster Prevention, Henan \\ Polytechnic University, Jiaozuo 454003, China \\ ${ }^{2}$ School of Mining Engineering, University of New South Walse, Sydney, NSW 2052, Australia
}

Received 29 March 2017; Accepted 30 August 2017

\begin{abstract}
Water content is one of the most significant factors affecting the rock deformation and strength characteristics in the rock enginnering. To reveal the deformation and strength characteristics of sandstone with different water contents, the compressive strength tests for sandstone specimens under four different confining levels were carried out and an exponential formulation was put forward to predict the reduction in cohesive strength with water content increasing. Results show that both the elastic modulus and peak stress of sandstone decrease appreciably with water content increasing, but the internal friction angle is independent of the water content. The reduction in compressive strength is mainly attributed to the decrease of the material cohesion. The conclusions obtained in the study are of important value to estimate the wet strength of porous rocks in rock engineering.
\end{abstract}

Keywords: Sandstone, Water content, Elastic modulus, Compressive strength

\section{Introduction}

Strength and deformation characteristics are crucial parameters for rock classification and design of near-surface or underground structures. Stability analysis of these structures using analytical or numerical approaches requires quantitative assessment on the elastic and failure characteristics. In many cases, such as dams and underground roadways in coal mines, which are easily exposed to surface rainfall or underground water, some rocks are weakened substantially after they are moistened with aqueous contents [1], [2].

At present, the unfavourable effect of water on different types of rock has been reported by many researchers. For example, Colback and Wiid observed that air-dried rocks could lose $50 \%$ of its original uniaxial compressive strength (UCS) after being saturated with water [3]. Martin tested eight different rock materials with varying moisture contents from an oven-dried to a saturated condition. Generally, the UCS decreased with increasing moisture contents, seemingly obeying a logarithmic relationship [4]. Similar strength reduction along with increased water ratio was also reported by Burshtein for sandstone and Van Eeckhout and Peng for shales in coal mines [5], [6]. Hawkins and McConnell investigated the influence of water content on the strength and deformability of 35 different British sandstones [7]. It was noted that the degree of sensitivity to moisture content was controlled primarily by the proportions of quartz and clay minerals present and to a less degree by the rock micro-

\footnotetext{
*E-mail addressw_sr88@163.com

ISSN: 1791-2377 @ 2017 Eastern Macedonia and Thrace Institute of Technology. All rights reserved. doi:10.25103/jestr.104.24
}

fabric. Later, Vásárhelyi and Ván revisited the published data in Hawkins and McConnell (1992) [8]. An empirical method was proposed for estimating the sensitivity of sandstone rocks to water content. However, the reason for UCS reduction caused by moisture was not appropriately explained. $\mathrm{Li}$ et al. observed that very low water contents markedly reduce the deformation and strength of metasedimentary rocks [9]. In addition, the reduction of strength by water content was reported relative to a variation of friction angle in the Mohr-Coulomb failure criterion. Besides the decrease in compressive strength, the peak shear stress also affected adversely with the presence of moisture [10]. Recently, Zhang and Zhao tested sandstone samples from dry to fully saturated state under triaxial loadings [11]. They suggested that the effect of water on the compressive strength of is becoming less remarkable with increasing confining pressures.

In a word, the relevant literatures on the moisture effect on UCS of different types of rocks are available, whereas the mechanical performance of rocks with varying water contents under triaxial loading remains an ongoing debate. So a systematic investigation on the compressive strength of Gosford sandstone from dry to fully saturated states under four different confining pressures was conducted. According to the analysis of the experimental results, an equation will be proposed to represent the reduction of compressive strength with increasing moisture contents. Moreover, the credibility of the proposed relationship will be illustrated by providing its correlation with experimental data.

The rest of this study is organized as follows. Section 2 describes the materials and methods, including sandstone samples, test apparatus and methods. Section 3 gives the result analysis and discussion, and finally, the conclusions are summarized in Section 4. 


\section{Materials and methods}

\subsection{Sandstone samples}

Gosford sandstone samples were collected from Gosford Quarry, Somersby, New South Wales in Australia. This rock forms a unit within the massive (290 m thick) Triassic Hawkesbury sandstone of the Sydney Basin. Gosford sandstone is typically a medium-grained $(0.2-0.3 \mathrm{~mm})$, poorly cemented, immature sandstone with minor quartz overgrowths and some iron staining. 20-30\% feldspar and clay minerals are contained within this sort of sandstone [12].

Gosford sandstone blocks were cored and cut into cylinder samples with height to diameter ratio averaged at 2.4. Specimens from nature dry to fully saturated state were prepared for uniaxial and triaxial compressive testing in accordance with the procedures provided by ISRM [13]. Table 1 shows the details of sandstone samples used in experiments.

Table 1. Basic information of prepared sandstone specimens

\begin{tabular}{c|r|r|r|r|r}
\hline Rock type & $\begin{array}{c}\text { Average height } \\
(\mathbf{m m})\end{array}$ & $\begin{array}{c}\text { Average } \\
\text { diameter } \mathbf{( m m )}\end{array}$ & $\begin{array}{c}\text { Average nature } \\
\text { weight } \\
(\mathbf{g})\end{array}$ & $\begin{array}{c}\text { Average saturated weight } \\
(\mathbf{g})\end{array}$ & $\begin{array}{c}\text { Water content ratio } \\
\mathbf{( \% )}\end{array}$ \\
\hline Gorsford sandstone & 100.56 & 41.74 & 292.54 & 308.54 \\
\hline
\end{tabular}

\subsection{Test apparatus and methods}

A MTS 815 Rock Mechanics Test System (Fig. 1) owned by the Geomechanics Laboratory, School of Mining Engineering, UNSW Australia, was employed to carry out compressive tests. This test system is ideal for uniaxial and triaxial rock tests in rock mechanics study. The highly stiff load frames offer high axial force capacity, with compression ratings up to $4600 \mathrm{kN}$ and tension ratings up to $2300 \mathrm{kN}$.

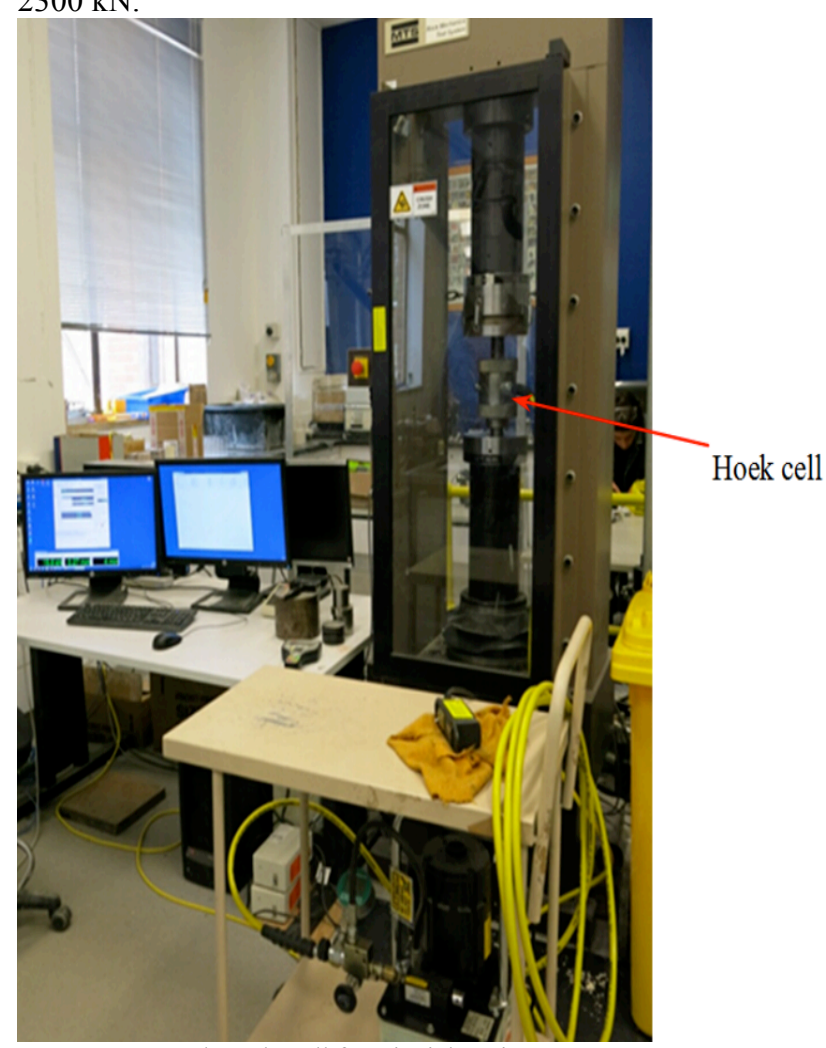

Fig. 1. MTS and Hoek Cell for triaxial testing

The loading speed is $0.001 \mathrm{~mm}$ per second with axial displacement control. Triaxial tests were realized by using a standard Hoek Cell that supplies uniform confining loadings. Confining stresses up to $15 \mathrm{MPa}$ were applied in the tests for sandstone with four different water content proportions. Each test was reproduced three times and the averaged values were used in the following analysis.

\subsection{Variation characteristics of compressive strength} Several strength criteria have been proposed for the intact rock under compressive loadings [14]. One of the most widely used one is the Mohr-Coulomb model that assumes the rock fails along a shearing plane, as illustrated by Fig. 3. According to Mohr-Coulomb failure envelope, the internal friction angle $\varphi$ and the cohesive strength $c$ can be obtained by plotting the confining pressures and corresponding strength values.

\section{Results and discussion}

\subsection{Variation characteristics of elastic deformation}

The average elastic modulus, which is the slope of the linear portion of the axial stress-strain curve, was used to represent the Young's Modulus (ISRM 1978). Fig. 2 clearly shows that the elastic modulus decreases with increasing water ratios. Under a higher confining pressure, the effect of moisture content is less remarkable. Specifically, in the unconfined compressive loading condition, the elastic modulus decreases substantially as the water content is increased. The quantitative reduction can be reasonably approximated by an exponential relationship (Fig. 2). Nevertheless, when the confining pressure is increased from 5.0 to $15.0 \mathrm{MPa}$, slight drop in Young's Modulus was observed. In other words, it seems that the elastic deformability of sandstone is less sensitive to the moisture contents than the confining pressures, being consistent with the results reported by Zhang and Zhao [11].

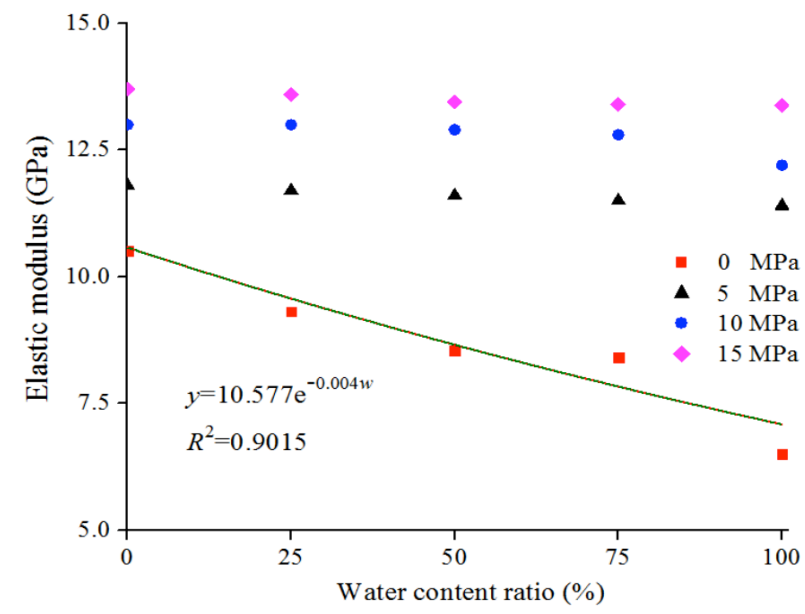

Fig. 2. Elastic deformability curve of sandstone with water contents increasing 


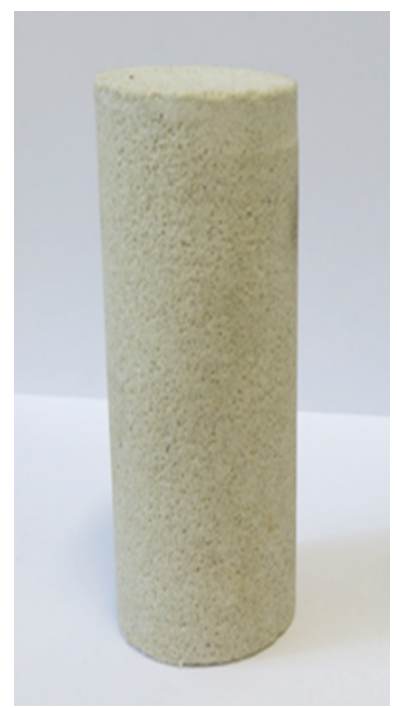

(a)

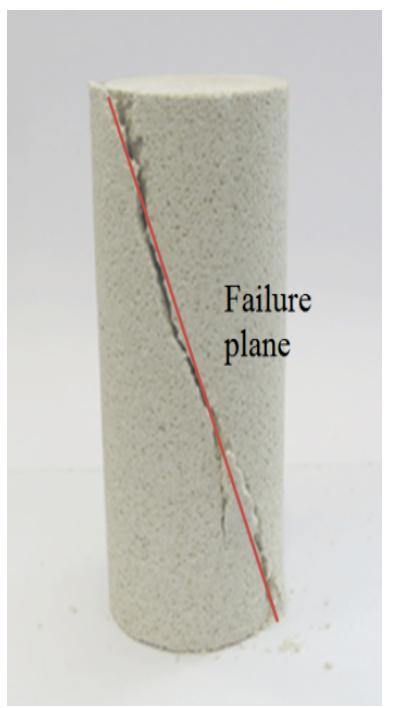

(b)

Fig. 3. The sandstone samples before and after test. (a) Before test. (b) After test

The following equations acquired from linear regression give the value of internal friction angle $\varphi$ and the cohesive strength $c$, respectively:

$\varphi=\arcsin \frac{m-1}{m+1}$

$c=b \frac{1-\sin \varphi}{2 \cos \varphi}$

where $m$ is the gradient and $b$ is the intercept at strength axis.

Fig. 4 illustrates the internal friction angle of the sandstone retains nearly the same $\left(45^{\circ}\right)$ under various degrees of water ratios. On the other hand, as seen noticeably in Fig. 5, the increase in moisture contained by the rock samples results into remarkable reduction for the material cohesion. Hawkins and McConnell reported that the relationship between water content and uniaxial compressive strength could be reliably described by an exponential equation. Since the cohesive reduction is the main factor contributing to the decrease in strength in compression, as indicated by comparing Fig. 4 to Fig. 5, it is reasonable to express the material cohesion $c$ reduces exponentially in a form similar to that in Hawkins and McConnell [7], i.e.:

$$
c=p e^{-q w}+r
$$

where $w$ is the water content ratio; $p, q$ and $r$ are material constants.

Consequently, the Mohr-Coulomb strength criterion can be modified as:

$$
\tau=c+\sigma_{n} \tan \varphi=\sigma_{n} \tan \varphi+p e^{-q w}+r
$$

where $\tau$ and $\sigma_{n}$ are the the shear strength and normal stress developed in the failure plane in a compressive test.

Significant reduction in the compressive strength of sandstone have been observed, which is in accordance to investigations frequently reported by Ojo and Brook, Hawkins and McConnell, Vásárhelyi, Vásárhelyi and Ván, Yilmaz and Zhang and Zhao [15], [7], [16], [8], [17], [11].

The compressive strength under four lateral loading magnitudes was calculated by Eq. (4). Table 2 details the values for the fitting parameters used in the formulation. A good agreement between predicted results and experimental data is presented by Fig. 6 .

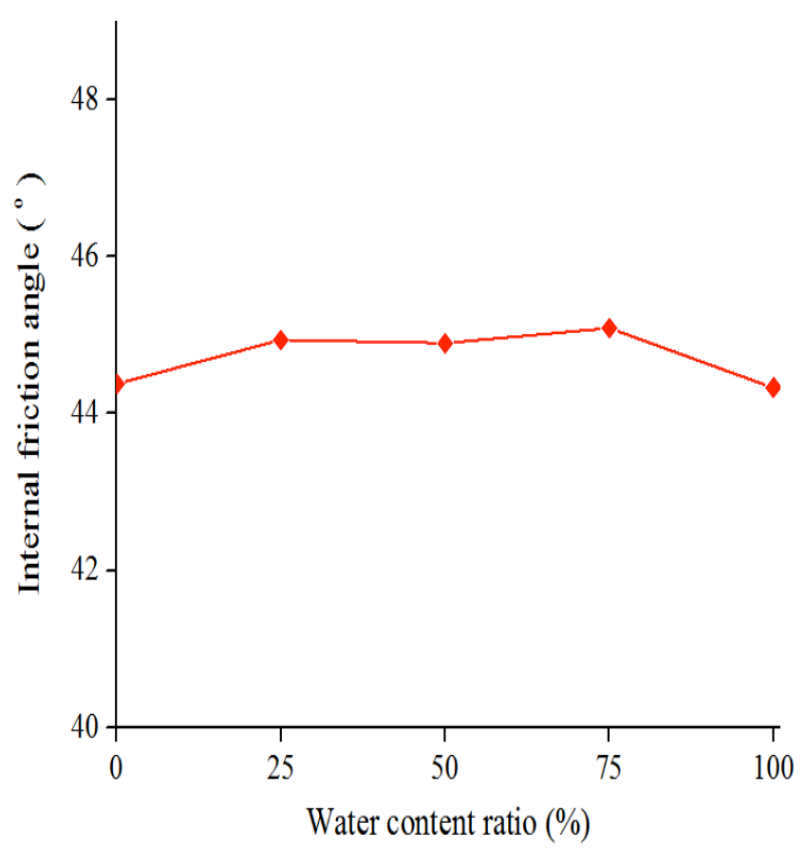

Fig. 4. Effect of water content on the internal friction angle of sandstone

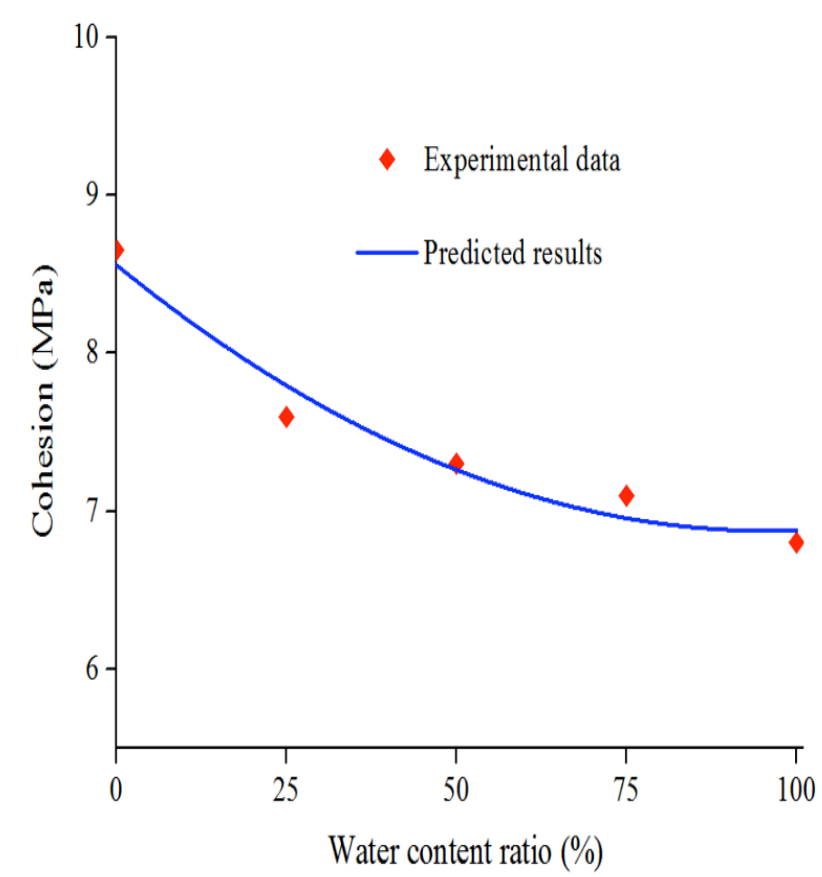

Fig. 5. The cohesive strength reduction with water content increasing

Table 2. Parameters of the four real-world networks

\begin{tabular}{c|c|c|c|c|c}
\hline Test type & Rock type & $p$ & $q$ & $r$ & $R^{2}$ \\
\hline $\begin{array}{c}\text { Conducte } \\
\text { d tests }\end{array}$ & $\begin{array}{c}\text { Gorsford } \\
\text { sandstone }\end{array}$ & 1.975 & 0.1734 & 6.704 & 0.970 \\
\hline $\begin{array}{c}\text { Tests by } \\
\text { Zhang and } \\
\text { Zhao } \\
(2014)\end{array}$ & $\begin{array}{c}\text { Balikun } \\
\text { sandstone }\end{array}$ & 17.44 & 0.004 & -2.003 & 0.960 \\
\hline
\end{tabular}




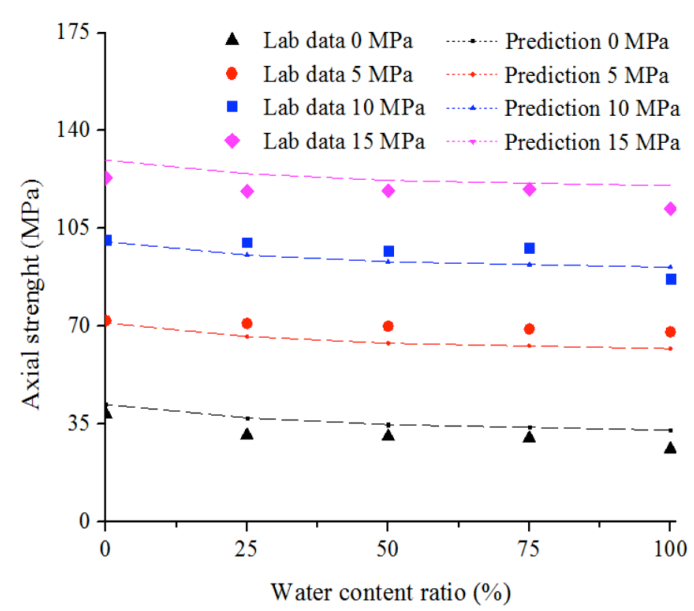

Fig. 6. Experimental compressive strength and predicted results under different confining pressures

Compression tests on sandstone samples collected from Balikun mine, Xinjiang Province, China, were performed by Zhang and Zhao under varied saturating degrees and confining pressures up to $30 \mathrm{MPa}$ [7]. Data analysis suggested that the internal friction angle of the Balikun sandstone is $34^{\circ}$, which is unaffected by the change of water contents. Figs. 7 and 8 compares the experimental results to the cohesion and compressive strength obtained by Eqs. (3) and (4). The parameter values are listed in Table 2. As can be seen in Fig. 8, the proposed equations achieved remarkable agreement with the results determined by laboratory tests.

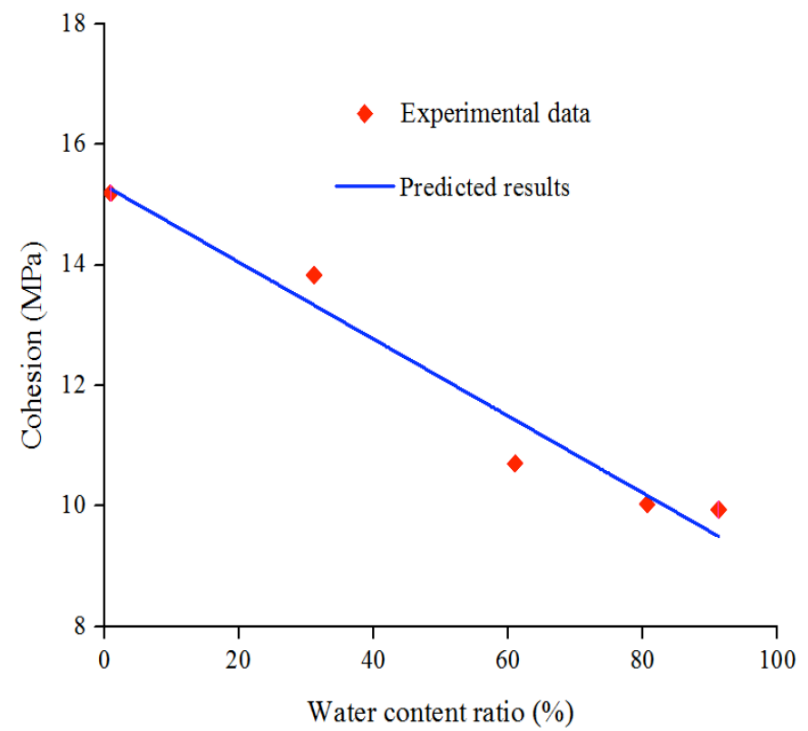

Fig. 7. Experimental cohesion and predicted results from Zhang and Zhao (2014)

At high lateral confinements, e.g. $15 \mathrm{MPa}$ in Fig. 6 and $30 \mathrm{MPa}$ in Fig. 8, the proposed Eq. (4) tends to undervalue the peak strength under triaxial compression. This is mainly due to that Mohr-Coulomb sliding criterion seems inapplicable in high lateral confinement regions. As suggested by Brady and Brown [14], peak strength envelopes of rocks observed experimentally are generally non-linear. In other words, linearity is only presented over limited ranges of lateral confining levels. Although other peak strength criteria featured with non-linear variation has been proposed, such as those by Bieniawski [18] and Hoek and Brown [19], the Mohr-Coulomb model retains being widely used in engineering design due to simplicity with explicit physical parameters, which are readily accessible from fundamental laboratory tests.

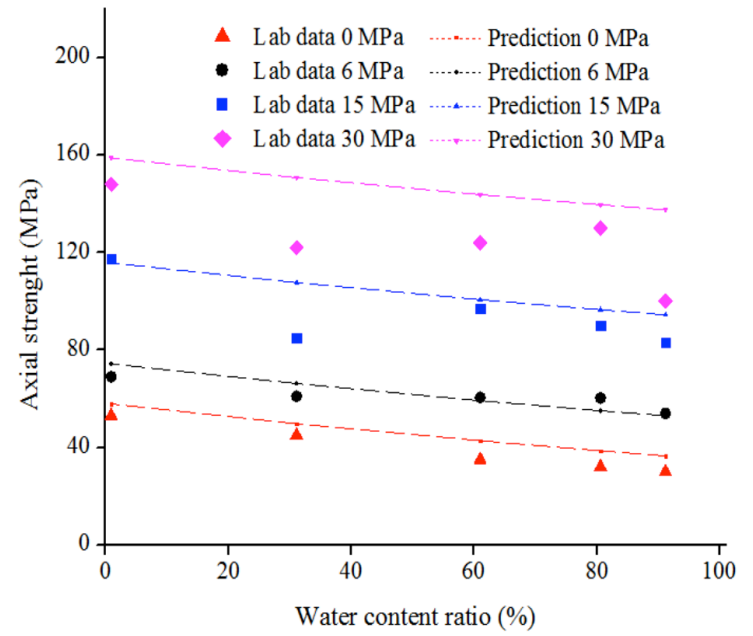

Fig. 8. Experimental comparison strength and predicted results from Zhang and Zhao (2014)

\section{Conclusions}

In the study, the theoretical analysis method and laboratory tests were adopted to evaluate the deformation and strength characteristics of sandstone with different water contents. The main conclusions could be drawn as following:

(1) The effect of water contents on the axial deformability and strength of Gorsford sandstone under different lateral loading conditions was revealed. Morover, we found that the peak strength reduction was caused by the decrease of mineralogical cohesion instead of the internal failure angle.

(2) An exponent formulation was put forward to represent the correlation between strength decrease and varying moisture ratios. The suggested formulation agrees closely with the results determined experimentally by the authors and those culled from the literature in terms of compressive strength tests.

(3) To estimate the wet strength of porous rocks in engineering design, the relationship suggested involving strength and water content ratio could serve as a criterion, which provides a good prospect to direct the rock strength design of sandstone with different water contents.

The present exploration are of important value to estimate the wet strength of porous rocks in rock engineering. But the constants involved in the predictive formulation are determined empirically, indicating that the sensitivity of differing sorts of sandstones to water could be inconsistent. Further studies on the response of various rock materials to moisture should be carried out experimentally.

\section{Acknowledgements}

This work was supported by the National Natural Science Foundation of China ((51774112; 51474188; 51474097), the International Cooperation Project of Henan Science and Technology Department (162102410027), the Doctoral Fund of Henan Polytechnic University (B2015-67), 2015 Australian Endeavour Research Fellowship, and Program for Taihang Scholars. All these were gratefully acknowledged.

This is an Open Access article distributed under the terms of the Creative Commons Attribution Licence 


\section{References}

1. Anvari, A. A., Katibeh, H., and Sharifzade, M., “A new approach for computing permeability of fault zones case study: the upper reservoir of Azad pumped-storage power station in Iran", Archives of Mining Sciences, 55(3), 2010, pp. 605-621.

2. Aristizabal, E. F. G., Jerez, C. A. R., and Brand, M. A. B., "Influence of rainfall intensity on infiltration and deformation of unsaturated soil slopes", Dyna, 78(170), 2011, pp. 116-124.

3. Colback, P. S. B., and Wiid, B., "The influence of moisture content on the compressive strength of rocks", In: Proceedings of the $3 r d$ Canadian symposium on rock mechanics, Toronto, Canada, 1965, pp. 65-83.

4. Martin, R. A., "The effect of moisture on the compressive and tensile strength on a variety of rock materials", Master thesis of Missouri University of Science and Technology, America, 1966, pp. 31-40.

5. Burshtein, L. S., "Effect of moisture on the strength and deformability of sandstone", Journal of Mining Science, 5(5), 1969, pp. 573-576.

6. Eeckhout, E. M. V., and Peng, S. S., "The effect of humidity on the compliances of coal mine shales", International Journal of Rock Mechanics and Mining Sciences \& Geomechanics Abstracts, 12(11), 1975, pp. 335-340.

7. Hawkins, A. B., and McConnell, B. J. "Sensitivity of sandstone strength and deformability to changes in moisture content", Quarterly Journal of Engineering Geology \& Hydrogeology, 25(2), 1992, pp. 115-130.

8. Vásárhelyi, B., and Ván, P., "Influence of water content on the strength of rock", Engineering Geology, 84(1-2), 2006, pp. 70-74.

9. Li, D. Y.,Wong, L. N. Y., Liu, G., and Zhang X. P., "Influence of water content and anisotropy on the strength and deformability of low porosity meta-sedimentary rocks under triaxial compression", Engineering Geology, 126, 2012, pp. 46-66.

10. Xu, J., Wu., H., Lu, L., Yang, H., and Tan, H., "Experimental study of acoustic emission characteristics during shearing process of sandstone under different water contents", Chinese Journal of Rock Mechanics \& Engineering, 31(5), 2012, pp. 914-920.
11. Zhang,C. H., and Zhao, Q. S., "Triaxial tests of effects of varied saturation and modulus for sandstone", Rock \& Soil Mechanics, 35(4), 2014, pp. 951-958.

12. Ord, A., Vardoulakis, I., and Kajewski, R., "Shear band formation in Gosford sandstone", International Journal of Rock Mechanics \& Mining Sciences \& Geomechanics Abstracts, 28(5), 1991, pp. $397-$ 409.

13. Bieniawski, Z. T., and Bernede M. J., "Suggested methods for determining the uniaxial compressive strength and deformability of rock materials: Part 1. Suggested method for determining deformability of rock materials in uniaxial compression", International Journal of Rock Mechanics and Mining Sciences \& Geomechanics Abstracts, 16(2), 1979, pp. 138-140.

14. Brady, B. H. G., and Brown, E. T., "Rock mechanics for underground mining", Springer, 1992.

15. Ojo, O., and Brook, N., "The effect of moisture on some mechanical properties of rock", Mining Science and Technology, 10(2), 1990, pp. $145-156$.

16. Vásárhelyi, B., "Some observations regarding the strength and deformability of sandstones in dry and saturated conditions", Bulletin of Engineering Geology, 62(3), 2003, pp. 245-249.

17. Yilmaz, I. "Influence of water content on the strength and deformability of gypsum", International Journal of Rock Mec hanics \& M ining Science, 47, 2010, pp. 342-347.

18. Bieniawski, Z. T., "Estimating the strength of rock materials", Journal-South African Institute of Mining and Metallurgy, 74(8), 1974, pp. 312-320.

19. Hoek, E., and Brown, E. T., "Practical estimates of rock mass strength",34(8), International Journal of Rock Mechanics \& Mining Science, 1997, pp. 1165-1186. 